\title{
PROFESSOR DR. HERBERT KRÜGER 70 JAHRE
}

Der Herausgeber dieser Zeitschrift, Professor Dr. Herbert Krüger, vollendet am 14. Dezember 1975 sein siebzigstes Lebensjahr. Mit freundlicher Bestimmtheit hat er sich der Absicht von Freunden und Schülern widersetzt, aus diesem Anlaß eine „Festschrift" $\mathrm{zu}$ veranstalten. Vielfältige andere Ehrungen - ein wissenschaftliches Kolloquium, Sonderhefte von Fachzeitschriften, Empfänge - zeigen, daß sich die wissenschaftliche Offentlichkeit selbst vom Jubilar nicht daran hindern läßt, seinen Geburtstag gebührend $z u$ feiern. Auch die Redaktion dieser Zeitschrift konnte dieses Datum nicht einfach übergehen. Als Gründer und Herausgeber von „Verfassung und Recht in Übersee“ hat Herbert Krüger sich unermüdlich für die Zeitschrift eingesetzt. Er hat in wichtigen Aufsätzen selbst zu Fragen der überseeischen Verfassungsvergleichung Stellung genommen, Freunde und Autoren gewonnen und die unerläßliche materielle Grundlage des Unternehmens gesichert.

Hinsichtlich der Form des Geburtstagsgrußes setzten die Wünsche des Jubilars der Redaktion allerdings Grenzen. Es sollte sich nicht um eine Ersatz-„Festschrift“" handeln. Dieses Doppelheft ist daher weniger der Person Herbert Krüger als vielmehr der Sache "Verfassung und Recht in Übersee“ gewidmet. Dabei kam es uns darauf an zu zeigen, daß die Zeitschrift gründlich überwunden hat, was ihm immer besonders verhaßt war: Provinzialität. Was bei der Gründung nur eine Hoffnung war, ist inzwischen Wirklichkeit: „Verfassung und Recht in Übersee“ ist ein internationales Forum für die Diskussion von Fragen von Recht und Entwicklung geworden. Dieses Heft, in dem Autoren aus den verschiedensten Ländern schreiben, beweist, daß der Freundes- und Autorenkreis heute weltweit ist. In dieser Funktion ist die Zeitschrift einmalig, denn alle ähnlichen Publikationen sind geographisch oder sprachlich viel enger festgelegt.

„Verfassung und Recht in Übersee“ überwindet Provinzialität, aber nicht nur im geographischen, sondern auch im disziplinären Sinn. An diesem Heft haben neben Juristen auch Anthropologen, Soziologen und Historiker mitgewirkt. Die Themen spannen sich vom Völkerrecht über das Verfassungsrecht bis zum Gesellschaftsrecht.

Als Illustrierung dieser geographischen wie fachlichen Breite der Zeitschrift erscheint dieses Sonderheft uns als ein angemessener Geburtstagsgruß für einen Wissenschaftler, der einer der bedeutendsten deutschen Rechtslehrer nicht durch Spezialisierung, sondern durch eine immer seltener werdende Universalität von Wissen und Interessen geworden ist.

Für die Redaktion: Brun-Otto Bryde Henning v. Wedel 